\title{
Actual Online Shopping Behavior among Jordanian Customers
}

\author{
Mohammed A. Al- Jabari ${ }^{1, *}$, Siti Norezam Othman ${ }^{2}$, Nik Kamariah Nik Mat ${ }^{1}$ \\ ${ }^{1}$ Othman Yeop Abdullah Graduate School of Business, Universiti Utara Malaysia, Sintok, 06010, Kedah Malaysia \\ ${ }^{2}$ College of Business, Universiti Utara Malaysia, Sintok, 06010, Kedah Malaysia
}

\begin{abstract}
Internet technology is becoming increasingly important in our daily life in general and in business world particularly. This increased role of the Internet encourages the researchers to investigate the customer behavior in this emerging market. The aim of this study is to examine the factors that give rise to the formation of the actual online shopping behavior of Jordanian customers. The study analyses the predictor variables of planned behavior among 313 university academic staff selected on the basis of probability sampling. Structural equation modeling (SEM) was used to analyze the causal relationships in accordance with the theory of planned behavior (TPB). The findings depicted that subjective norm and perceived behavioral control to have significant positive effects on intention. Attitude has no direct significant impact on online shopping intention. Online shopping intention also has a positive and significant impact on actual online shopping behavior. The practical implication of the research is discussed.
\end{abstract}

Keywords Online Shopping Behavior, Theory of Planned Behavior, Intention, Attitude, Subjective Norms, Perceived Behavior Control, Jordan

\section{Introduction}

Internet purchasing has been predicted to escalate with the increase of internet users around the globe. For example internet users worldwide has spiralled from 655 million in 2002 to 941 million users in 2005[1]. The proliferation of commercial web sites providing consumers with a new medium to purchase products and services and brings many diverse buyers and sellers together globally. According to Aslanbay et al[2], this digitized century has also changed consumer dynamics and consumption behaviors. The increasing role of the Internet in daily life extends the research towards this emerging market and changing customer behaviors. Companies facing the challenge of customer acquisition are searching for ways to predict the factors that lead to actual purchases on the Internet[3].

Theory of Planned Behavior (TPB) $[4,5]$ is an extension of the theory of reasoned action (TRA)[6]. TPB is a well-reputed framework "for conceptualizing, measuring, and empirically identifying factors that determine behavior and behavioral intention"[7].

Research on TPB usually focuses on predicting factors of behavior within the traditional marketing environment rather than the Internet. In addition, Theory of Planned Be

* Corresponding author:

m_aljabari1@yahoo.com (Mohammed A. Al- Jabari)

Published online at http://journal.sapub.org/economics

Copyright (C) 2012 Scientific \& Academic Publishing. All Rights Reserved havior to predict online shopping intention has been examined in developed countries, however limited evidence is found in developing countries.

According to TPB, behavior is determined by the individual's intention to perform the behavior, intention is determined by three factors; attitudes toward the behavior, which are informed by beliefs needed to engage in the behavior[5]; subjective norm, the social pressures to perform or not to perform the behavior and perceived behavioral control refers to people's perceptions of their ability to perform a given behavior[5]. TPB have been applied to a wide variety of behaviors over the years, including tourism[8], internet banking[9], Internet stock trading[10] and e-commerce[11]. However, little research exists that considers customer' behavior in developing countries when shopping via the Internet.

According to Internet World Stats report, the Internet usage rate of Jordan has increased from $14.8 \%$ in 2007 to $27.2 \%$ in 2010 [12]. Understanding the relative importance of predictor variables (such as attitude towards the behavior, subjective norms and perceived behavioral control that lead to the desired behavior helps online companies formalize company strategies in increasing customer visits, purchases and purchase again. In addition, understanding why people accept or reject computer systems such as online shopping has proven to be one of the most challenging issues in information system research especially in Jordan. Further, there are limited empirical studies related to online shopping in Jordan. 


\section{Predictors of TPB}

TPB postulates four conceptually independent determinants of actual behaviour (1) attitude; it is defined as Individual's positive or negative feeling associated with performing a specific behavior. Ajzen and Fishbein[6] suggest that people form beliefs about an object by associating it with various characteristics, qualities and attributes. Because of these beliefs, they acquire favorable or unfavorable attitudes toward that object depending on whether they associate that object with positive or negative characteristics. Several past studies had found a significant direct relationship between attitude and intention, in internet banking for example, Celik[13] found that attitude is significantly related to internet banking intention. Moreover, Chai and Pavlou[14] found that attitude is a significant predictor of ecommerce intention. (2) Subjective norms refer to an individual's perception of whether people who are important to him or her think that he or she should or should not perform the behavior in question[6]. They are the function of how a consumers' referent others (e.g., family and friends) view the regarding behavior and how motivated the consumer is to comply with those beliefs[15]. Previous studies show an inconsistent finding regarding the effect of subjective norm on intention. Nik Kamariah \& Sentosa[16], Al-Majali[17] and Karami[18] found significant effects of subjective norm on intention, while $\operatorname{Lin}[19]$ found that there is no effect. On the other hand, Armitage and Conner[20] showed that subjective norms were a weak predictor of behavioral intentions. (3) Perceived behavioral control, it is defined as an individual's confidence that he or she is capable of performing the behavior[21]. The perception of volitional control or the perceived difficulty towards the behavior will affect intent[22]. Unless, control over a behavior exists, intentions will not be sufficient as the predictor of the behavior[23]. Factors such as skills, abilities, time, and requisite information play a significant role in predicting and performing the behavior. Nik Kamariah and Sentosa[16], Lee[9] and Karami[18] found that the effect of perceived behavioral control on intention was significant. Hansen et al.[24] found an insignificant effect of behavioral control on intention among Danish samples. In terms of the relationship between perceived behavioral control and actual behavior, previous studies found a positive and significant effect $[25,26]$. (4) Intention is an important factor in understanding behavioral tendency before a particular behavior is adopted. Behavioral intention refers to the expression induced during the decision process; this expression often tells whether certain behavior will be adopted or not. Behavioral intention is a necessary process in any form of behavior expression; it is a decision made before an actual behavior is adopted[27].

The researcher finds Jordanian customer' willingness, particularly actual online shopping behavior to be one of the major issues that should be investigated in the Jordanian context. This is because the intention and actual of online shopping behavior is very crucial for the economic and e-commerce growth in the country. Since this factor is one of the most important factors that determine the final actual usage, most previous research in online shopping and different setting found significant and positive relationship between intention and actual[16, 28-30]. However, only few studies investigating the effect of intention on actual behavior in Jordan using Unified Theory of Acceptance and Use of Technology (UTAUT) model[28] and[17], both studies have conducted in internet banking. Thus, there is still a lack of studies that have used the TPB model to examine this linkage in Jordan, particularly in online shopping setting.

Therefore, in a Jordanian context, more focus should be given to the actual online shopping behavior and intention of the customer in order to help online companies, marketing managers and law-makers learn more about the importance of such aspects in the national economy and marketing. Previous studies indicated to the effect of intention on actual behavior in different settings[8, 16, 19, 31].

Based on the above explanations the following hypothesis are formulated:

H1: Attitude towards the behavior has a significant and positive direct effect on behavioral intentions of academic staff shopping via the Internet.

$\mathrm{H} 2$ : Subjective norms have a significant and positive direct effect on behavioral intentions of Jordanian customers shopping via the Internet.

H3: Perceived behavioral control has a significant and positive direct effect on online shopping intentions of among Jordanian customers.

H4: Perceived behavioral control has a significant and positive direct effect on actual online shopping behavior.

H5: online shopping intention has a significant and direct positive effect on actual online shopping behavior.

\section{Methodology}

Based on the findings of Ndubisi and Sinti[32], it can be said that respondents with higher income and better education like lecturers are more likely to use online shopping than other groups of customers. Indeed, consumers' income levels and education play a vital role in their adoption and usage of internet services. In addition, and according to Grabner-Kräuter and Kaluscha[33], students are not representative of the entire Internet consumers' population, and therefore they suggest that the results of Jarvenpaa et al's[34] study may not be generalised to other types of customers.

Data for the research were collected from a sample of university academic staff at a Jordanian universities using a probability sampling procedure. A self-administered structured questionnaire was developed to collect data pertaining to the various aspects of behavioral intention. Responders provided evaluations on the attitude towards the behavior factor by answering (seven items). Subjective norms (seven items), perceived behavioral control (seven items) and in- 
tention (eight items) were measured on a seven-point Likert scales ( $1=$ strongly disagree; 7 = strongly agree). In addition to questions related to demographic information.

This study used the SPSS software for determining the internal consistency. The results of Cronbach's Alpha value ranged from 0.94 and 0.95 . The results of composite reliability ranged between .97 to .99 that exceeds 0.70 which indicates adequate internal consistency[35]. To test convergent validity, exploratory factor analysis (EFA) was conducted, and average variance extracted (AVE) was calculated for discriminant validity. The results of the Variance Extracted (VE) test for all the constructs are ranged from 0.97 to 0.99 , which above the recommended value of .50[36].

Average variance extracted value for all the constructs were calculated by averaging the variance extracted of two constructs. For discriminant validity to be upheld, it has been suggested that AVE should be greater than .50 in order to justify using a construct[37]. All the constructs' AVE is above the recommended value (.50). According to Farnell and Larcker[36], the AVE should be greater than squared correlation to achieve discriminant validity. Discriminant validity was demonstrated, as the AVE values were more than the squared correlations for each set of constructs. Moreover, it can be observed that the square root of the AVE for a given construct is greater than the absolute values of the standardized correlation square of the given construct with any other construct in the analysis. Thus, discriminant validity is supported and therefore all constructs used for this study are different from each other.

Confirmatory factor analysis result shows that the factor loadings of all observed variables or items are adequate ranging from 0.74 to 0.93 . The factor loadings or regression estimates of latent to an observed variable should be above 0.50 (Hair et al., 2006). This indicates that all the constructs conform to the construct validity test. The remaining numbers of items for each construct are as follows: Attitude (5 items), Subjective norms (5 items), Perceived behavior control (6 items), Intention (5 items) and actual behavior (3). All CFAs of constructs produced a relatively good fit as indi- cated by the goodness of fit indices such as CMIN/df ratio $(<2)$; Goodness of Fit Index GFI $(\geq .90)$; TLI $(\geq 0.90)$; CFA $(\geq .90)$ and root mean square error of approximation RMSEA of values $(<.08)$.

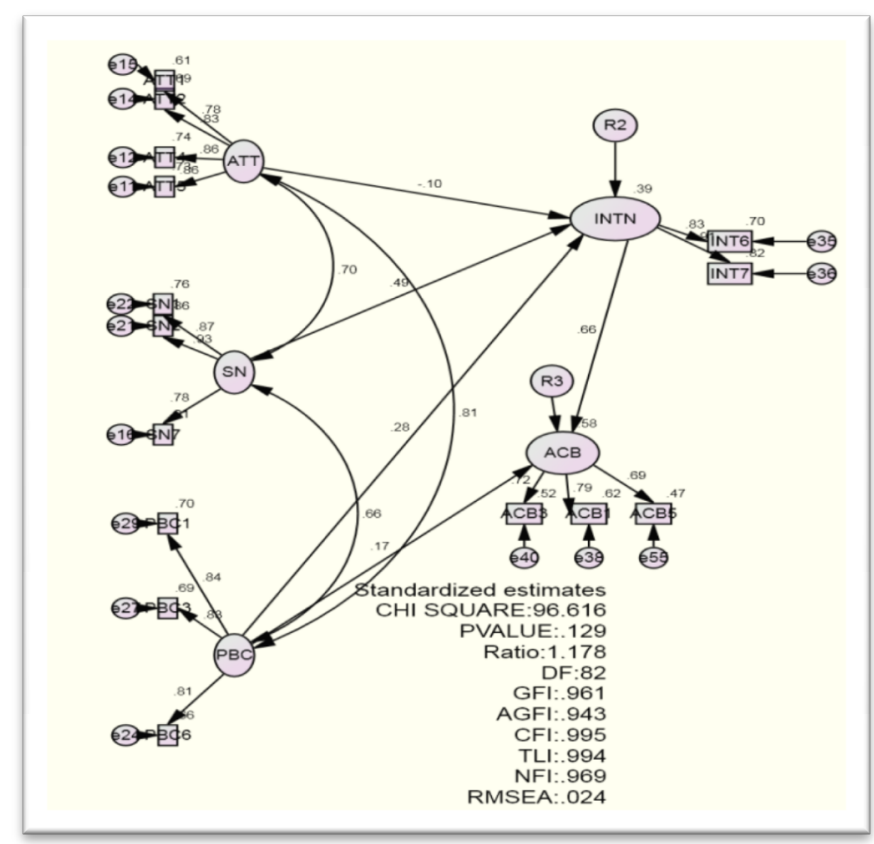

Figure 1. TPB Revised Model

Parameter C.R, estimate and S.E of the revised model are exhibited in Table 1 . The results show that insignificant relationships between attitude and intention $(\beta=-0.099$, C.R $=-.844$ and $\mathrm{p}=0.399$ ) or $\mathrm{H} 1$ is rejected. Subjective norm has a positive and significant effect on intention supporting $\mathrm{H} 2$, ( $\beta=0.492$, C.R $=5.662)$. The effect of perceived behavior control on intention (H3) also is supported $(\beta=0.275, \mathrm{C} . \mathrm{R}=$ 2.424 and $p=0.015$ ). The effect of perceived behavior control of actual behavior $(\mathrm{H} 4)$ is supported $(\beta=0.166, \mathrm{C} . \mathrm{R}=$ $2.53)$. The results show that intention has a significant and positive influences on actual behavior $(\beta=.664, C . R=8.594)$, this means that $\mathrm{H} 5$ is supported.

Table 1. Regression Weight

\begin{tabular}{ccccccccc}
\hline & & Estimate & S.E. & C.R. & P & Label \\
INTN & $<---$ & ATT & -0.099 & 0.105 & -0.844 & 0.399 & par_13 \\
INTN & $<---$ & SN & 0.492 & 0.089 & 5.662 & $* * *$ & par_14 \\
INTN & $<---$ & PBC & 0.275 & 0.106 & 2.424 & 0.015 & par_15 \\
ACB & $<---$ & INTN & 0.664 & 0.075 & 8.594 & $* * *$ & par_12 \\
ACB & $<---$ & PBC & 0.166 & 0.06 & 2.53 & 0.011 & par_16 \\
\hline
\end{tabular}




\section{Conclusions and Future Recommendation}

This study attempts to examine the goodness of fit of the TPB hypothesized model. As expected, the hypothesized model does not achieve model fit ( $\mathrm{p}$ value=.000). This implies that hypothesized model was not supported. However, the revised model accomplished model fit and supports two direct effects. Firstly, the attitude was not having a direct significant impact on online shopping behavior. This is similar to Fusilier and Durlabhji[38] finding for their studying in internet banking setting. Past studies have obtained different results[13, 14, 31, 39]. Those who have a positive attitude about online shopping do not necessary going to purchase online. Second, subjective norms have a direct significant effect on intention. Previous studies[14, 16] have found similar finding while George[39] found otherwise. This could imply that families, friends and referent others could have a certain amount of influence on intention to purchase on-line rather than on the actual purchasing behavior. Thirdly, perceived behavior control has a direct and positive effect on online shopping intention. This is supported by numerous past studies[10, 30, 39, 40]. Fourthly, perceived behavior control has a direct and positive effect on actual online shopping behavior. In consist with previous studies[18, 25], this study found that intention has direct and positive effect on actual behavior

For future research, it is important to include the younger generation, like university students in future research as they represent a high percentage of internet users. In addition, as online shopping is almost similar to internet banking, future research can be done for comparison between two settings. Future research can be conducted to examine the effect of culture on actual online shopping behavior. Finally, comparison between two different cultures (Jordan and others) is strongly recommended.

\section{ACKNOWLEDGEMENTS}

We would like to thank Prof Dr. Nik Kamariah Nik Mat and Sukma Pea for their helpful comments and assistance on an earlier version of this paper.

\section{REFERENCES}

[1] R. Dholakia and O.Uusitalo, "Switching to electronic stores: consumer characteristics and the perception of shopping benefits," International Journal of Retail and Distribution Management, 30, 10 (2002).

[2] Y. Aslanbay, M. Aslanbay, and E. Çobanoğlu, "Internet addiction among Turkish young Consumers," Young Consumers, 10, 1 (2009).

[3] D. Hoffman and T. Novak, "How to acquire customers on the web," Harvard Business Review, 78, 3 (2000).
[4] I. Ajzen, From intentions to actions: A theory of planned behavior. Springer- Verlag: Berlin and New York (1985).

[5] I. Ajzen, "The theory of planned behavior," Organizational behavior and human decision processes, 50, (1991).

[6] I. Ajzen and M. Fishbein, Understanding attitudes and predicting social behavior. Prentice-Hall: Englewood Cliffs, NJ (1980).

[7] I. Vermeir and W. Verbeke, "Sustainable food consumption among young adults in Belgium: Theory of planned behavior and the role of confidence and values," Ecological Economics, 64, (2008).

[8] A. Al-Muala, "Antecedents and mediator of actual visit behavior amongst international tourists in Jordan," ph.D thesis, College of Business, UUM, Malaysia (2010).

[9] M. Lee, "Factors influencing the adoption of internet banking: An integration of TAM and TPB with perceived risk and perceived benefit," Electronic Commerce Research and Applications, 8, (2009).

[10] M. Gopi and T. Ramayah, "Applicability of theory of planned behavior in predicting intention to trade online, Some evidence from a developing country," International Journal of Emerging Markets, 2, 4 (2007).

[11] A. Crespo and I. Bosque, "The effect of innovativeness on the adoption of B2C e-commerce: A model based on the Theory of Planned Behavior," Computers in Human Behavior, 24, 6 (2008).

[12] Internet World Statistics. Internet usage in the Middle East. Available: www.internetworldstats.com $/ \mathrm{me} / \mathrm{jo.htm}$

[13] H. Celik, "What determines Turkish customers' acceptance of internet banking?," International Journal of Bank Marketing, 26, 5 (2008).

[14] L.Chai and P. Pavlou, "From Ancient to Modern: A Cross-Cultural Investigation of Electronic Commerce Adoption in Greece and the United States " Journal of Enterprise Information Management, 17, 6 (2004).

[15] H. Lim and A. Dubinsky, "The Theory of Planned Behavior in E-Commerce: Making a Case for Interdependencies between Salient Beliefs," Psychology \& Marketing, 22, 10 (2005).

[16] N. N. Mat and I. Sentosa, "The integration of theory of planned behavior (TPB) and technology acceptance model in internet purchasing: a structural equation modeling (SEM) approach," Proceedings of Applied International Business Conference, 2008.

[17] M. Al-Majali, "The antecedents of internet banking service adoption in Jordan: using decomposed theory of planned behavior," ph.D thesis, College of Business, UUM, Malaysia (2011).

[18] M. Karami, " Factors influencing adoption of online Ticketing," Master thesis, Lulea University of Technology, (2006).

[19] H. Lin, "Predicting consumer intentions to shop online: An empirical test of competing theories," Electronic Commerce Research and Applications, 6, (2007).

[20] C. Armitage and M. Conner, "Efficacy of the theory of 
planned behavior: A meta-analytic review," British Journal of Social Psychology, 40, (2001).

[21] I. Ajzen. (2006, Constructing a TPB Questionnaire: Conceptual and Methodological Considerations. Available at: http://www.people.umass.edu/aizen/pdf/tpb.measurement.pd f

[22] M.Chang, " Predicting Unethical Behavior; A Comparison of the Theory of Reasoned Action and the Theory of Planned Behavior," Journal of Business Ethics, 17, 16 (1998).

[23] A. Sahni, "Incorporating Perceptions of Financial Control in Purchase Prediction: An Empirical Examination of the Theory of Planned Behavior," Advances in Consumer Research, 21, (1994).

[24] T. Hansen, J. Jensen, and H. Solgaard, "Predicting online grocery buying intention: a comparison of the theory of reasoned behavior and the theory of planned behavior," International Journal of Information Management, 24, (2004).

[25] Y. Chu and T. Wu, "In-Depth Citizen Interaction with E-Government from Taxpayers' Behavioral Perspective," International Journal of the Information Systems for Logistics and Management, 1, 1 (2005).

[26] B. Jaruwachirathanakul and D. Fink, "Internet banking adoption strategies for a developing country: the case of Thailand," Internet Research, 15, 3 (2005).

[27] M. Fishbein and I. Ajzen, Belief, attitude, intention, and behavior: An introduction to theory and research. Addison-Wesley: Reading, MA (1975).

[28] K. Al-Qeisi, "Analyzing the use of UTAUT model in explaining an online behaviour: internet banking adoption," Doctoral dissertation, Brunel University, UK (2009).

[29] M. Tan and T. Teo, "Factors influencing the adoption of internet banking," Journal of the Association for Information Systems, 1, 5 (2000).
[30] Y. Shih and K. Fang, "The use of decomposed theory of planned behavior to study internet banking in Taiwan," Internet Research, 14 3(2004).

[31] J. George, "The theory of planned behavior and Internet purchasing," Internet Research, 14, 3 (2004).

[32] N. Ndubisi and Q. Sinti, "Consumer attitudes, system's characteristics and internet banking adoption in Malaysia " Management Research News, 29, 1/2 (2006).

[33] S. Grabner-Kräuter and E. Kaluscha, "Empirical research in on-line trust: a review and critical assessment," International Journal of Human-Computer Studies, 58, 6 (2003).

[34] S. Jarvenpaa, J. Tractinsky, and M. Vitale, "Consumer trust in an internet store," Information Technology and Management, 1, 1\&2 (2000).

[35] J. Hair, R. Andersen, R. Tatham, and W. Black, Multivariate Data Analysis, 5 ed. Prentice-Hall: New Jersey (1998).

[36] C. Farnell and D. F. Larcker, " Evaluating structural equation models with unobservable variables and measurement error," Journal of Marketing Research 18, 1 (1981).

[37] D. Barclay, R. Thompson, and C. Higgins, "The partial least squares (PLS) approach to causal modelling: personal computer adoption and use as an illustration," Technology Studies, 2, 2 (1995).

[38] M. Fusilier and S. Durlabhji, "An exploration of student internet use in India, the technology acceptance model and the theory of planned behavior," Campus-Wide Information Systems, 22, 4 (2005).

[39] J. George, "Influences on the intent to make internet purchases," Internet Research: Electronic Networking Applications and Policy, 12, 2 (2002).

[40] V. Venkatesh, M. Morris, G. Davis, and F. Davis, "User acceptance of information technology: toward a unified view," MIS Quarterly, 27, 2 (2003). 